\title{
Recruitment of HIV-Positive Women in Research: Discussing Barriers, Facilitators, and Research Personnel's Knowledge
}

\author{
Mona R. Loutfy ${ }^{*}, 1,2$, V. Logan Kennedy ${ }^{1}$, Saira Mohammed ${ }^{1}$, Wei Wu ${ }^{1}$, Marvelous Muchenje ${ }^{3}$, \\ Khatundi Masinde ${ }^{1}$, Khaled Salam ${ }^{4}$, Lena Soje ${ }^{5}$, Sandra Gregorovich ${ }^{6}$ and Wangari Tharao ${ }^{3}$ \\ ${ }^{I}$ Women's College Research Institute, Women's College Hospital, Toronto, Ontario, Canada \\ ${ }^{2}$ Department of Medicine, University of Toronto, Toronto, Ontario, Canada \\ ${ }^{3}$ Women's Health in Women's Hands Community Health Centre, Toronto, Ontario, Canada \\ ${ }^{4}$ AIDS Committee of Ottawa, Ottawa, Ontario, Canada \\ ${ }^{5}$ Black Coalition for AIDS Prevention, Toronto, Ontario, Canada \\ ${ }^{6}$ Faculty of Medicine, McMaster University, Toronto, Ontario, Canada
}

\begin{abstract}
Background: Women have historically been under-represented in HIV research, partly due to ineffective recruitment strategies.

Objective: To improve the existing understanding of recruitment for HIV-positive women based on a province-wide crosssectional study.

Methods: A survey was emailed to all site coordinators who recruited participants in a study involving 490 HIV-positive women living in Ontario, Canada. The survey consisted of questions regarding the important recruitment barriers and successes. Quantitative data were then contextualized within extensive knowledge from research personnel and team members.

Results: Completed surveys were received from (89\%) site coordinators (34/38) and 98\% (31/34) were women. The highest ranked recruitment barriers identified were: sensitivity of the research topic (59\%), time/availability constraints (59\%), language barriers (53\%), HIV disclosure/stigma issues (47\%), lack of trust of research personnel (41\%), fear of research $(41 \%)$ and inaccessibility to child care and transportation $(41 \%)$. The respondents felt that the most important personal attributes for recruitment were research personnel who were respectful (97\%), skilled (91\%), flexible (88\%) and empathetic (88\%) and had good communication skills (88\%). The most successful recruitment strategies identified were: developing a strong rapport (88\%) that was facilitated by an empathetic relationship (100\%), acknowledging the sensitive nature of the research topic (94\%), providing cash financial compensation (88\%), and developing recruitment strategies unique to women $(88 \%)$.

Conclusion: There are differences in the approaches needed for the recruitment of HIV-positive women in research. For successful recruitment of HIV-positive women, a strong rapport between the research personnel and study participants is important. This rapport is facilitated by having study personnel who are respectful, trustworthy, empathetic, and flexible. Population-specific recruitment strategies are important to ensure adequate recruitment of minority groups in research with greater gender consideration for women requiring specific attention.
\end{abstract}

Keywords: AIDS, clinical research, HIV, recruitment, women.

\section{INTRODUCTION}

\section{Recruitment Issues in Research}

With growing pressure from funding agencies, industry, and other research stakeholders, the spotlight on equitable recruitment in research has grown considerably in recent years [1]. What was once largely a white, privileged, male

*Address correspondence to this author at the Women's College Research Institute, Women's College Hospital, 790 Bay Street, Room 736, Toronto, Ontario M5G 1N8 Canada; Tel: 416-351-3732, Ext. 2324;

Fax: 416-351-3746; E-mail: mona.loutfy@wchospital.ca domain, research is now being called upon to expand its reach and ensure the equitable inclusion of many minority groups. Research lacking minority groups, be it a clinical trial or any other form of research, is widely criticized for issues with validity, reliability, and generalizability in the absence of such groups [2-6]. Women represent one such group. Research into the recruitment of minority, underrepresented groups reveals interconnected issues between societal challenges, recruitment approaches and individual factors of potential study participants [7]. These interconnected challenges with recruitment seem to pose a particular problem in the recruitment of HIV-positive 
women, specifically those who exist at the intersection of HIV and other forms of stigma $[3,7,8]$

\section{Recruitment of HIV-Positive Women in Research}

Despite the fact that the first published literature on the subject of low enrolment of HIV-positive women in research dates back to the mid 1990s, ongoing studies continue to demonstrate that women's enrolment and retention in HIV research is unacceptably low $[6,9,10]$. This is an important issue that needs to be addressed now more than ever as the Canadian, American and global statistics indicate that women now account for 23\%, 25\% and 54\% (among adults) of the HIV prevalence, respectively [11-13].

Despite the growing prevalence of HIV research that focuses on or includes women, reports exploring recruitment challenges in this population remain largely anecdotal, particularly among racial and ethnic minority women [2, 1418]. The published literature addressing recruitment barriers is also largely limited to HIV clinical trials and does not include observational studies and community-based studies $[6,19-21]$ nor does it focus on specific racial and ethnic minorities or women $[3,7,15,22]$. There is some research that has explored the role of gender in HIV research recruitment [7, 14]. In the first published article on this topic, low enrolment of women was critique at a societal level, an institutional level, and at the personal level of women [7]. In a US report, individual and population level recruitment strategies were explored and found that direct, personal recruitment was more effective at recruiting and retaining woman than large media type campaigns [14].

In May 2010, AIDS published a commentary which stated that the recruitment and inclusion of women in HIV clinical trials should be an urgent priority for researchers given their historically low participation in light of gender parity in the epidemic [22]. This statement, and similar publications, has highlighted that issues beyond inclusion/exclusion criteria needed to be considered and successful approaches need to be reaffirmed through different research efforts [22, 23].

\section{Theoretical Approach}

We report findings uncovered through an iterative, community-informed approach to data analysis and reporting. An iterative approach, typically cited in qualitative research, is based in the fundamental principle that research is a cyclical process whereby emerging data inform changes and additions to research objectives [24]. Basic theoretical tenants include early review of data, flexibility in methodology and data collection procedures, and repeated analysis in order to respond to the units of data as they emerge [24].

We used this approach to explore the available data on continued challenges in the recruitment of HIV-positive women that our research program was experiencing. The purpose of this study was to learn from research personnel's knowledge base to assess recruitment barriers and identify successful recruitment strategies for HIV-positive women. First, we developed a survey to collect data on the perspectives of research personnel who did the primary recruitment for a cross-sectional survey on fertility intentions among HIV-positive women of reproductive age in Ontario,
Canada [25]. Then, in our analysis we have aimed to contextualize these findings by situating them in information we have available from members of our Project Advisory Committee (which included the investigators, central coordinator, site research personnel, and community members) from the original cross-sectional study.

\section{METHODS}

\section{Original Cross-Sectional Study Description}

The Ontario HIV Fertility Study [25] was initiated to investigate in HIV-positive women of reproductive age living in Ontario: 1) their desire to have children and intentions of becoming pregnant; 2) their need to access family planning and fertility clinics; and 3) their belief whether the general medical community is supportive of HIV-individuals having children. Four hundred and ninety women living with HIV of reproductive age living in Ontario were enrolled from 38 sites across the province of Ontario from October $5^{\text {th }}, 2007$ to March $31^{\text {st }}, 2009$ [25].

\section{Current Participants}

We approached the single assigned research staff member at each of the 38 sites who carried out the screening and recruitment of study participants. The primary inclusion criteria were: 1) being the assigned staff member that recruited for the Ontario HIV Fertility Study [25] and 2) the ability and willingness of the study site personnel to participate. The sites included 28 Community-based AIDS Service Organizations (ASO), 1 Community Health Centre (CHC), and 9 HIV Clinics from across Ontario. The research personnel consisted of 7 research coordinators, 2 research assistants, 14 support service workers or coordinators, 4 case/project managers, 5 nurses, and 2 executive directors.

\section{Procedures}

An eight-page survey was administered by the Ontario HIV Fertility Study Central Research Coordinator by an email invitation. The cover page of the survey and the email sent indicated that their participation and results would be kept in strict confidence and they are not to put their name anywhere on the survey. Participants were given the option of either emailing the scanned completed survey or faxing the survey back to the central coordinator. The survey took approximately 10 to 15 minutes to complete and asked questions related to demographics, recruitment barriers, and successful recruitment strategies.

\section{Ethics}

Since the survey included no personal identifiers and was completed by organizational staff, consent was implied by completing and submitting the final document. The Women's College Research Institute Research Ethics Board approved the survey and procedures. Also, all study activities were conducted following the principles of the 2008 version of the Declaration of Helsinki (Seoul, Korea).

\section{Identification of Perceived Recruitment Barriers and Strategies by Research Personnel}

During enrolment for the Ontario HIV Fertility Study, various recruitment strategies were used to enrol participants from the 38 sites across Ontario. These strategies included 
posters, direct enrolment (study coordinators approached eligible participants during clinical or service related visits), linking enrolment to community peer gatherings and forums, snowball sampling, and chart review for eligibility. Members of the Project Advisory Committee attended meetings to monitor the progress of the project once enrolment had begun. These meetings were an important aspect of the iterative approach to our research process and were used as an opportunity to identify, discuss, and address issues regarding recruitment/enrolment and to provide feedback on all aspects of the project as it progressed. The site research personnel offered insight into several recruitment barriers and strategies during these meetings. After the meetings, the central coordinator highlighted the effective recruitment strategies identified and recommended them to all site research personnel for the project. Several sites were able to implement these strategies to increase recruitment while others were unable to do so for logistical reasons. These barriers and strategies were also used to develop the survey used in the current study.

\section{Statistical Analysis}

Data from the eight-page survey were entered twice and verified prior to analysis. Statistical analyses were performed using SAS Version 9.1.3 (SAS Institute, Cary, North Carolina, USA). Baseline characteristics of the study population were summarized using means and SD for continuous variables and frequencies and proportions for categorical variables. The identification of the recruitment barriers and strategies and the attributes of research personnel for successful recruitment that were deemed to be important were reported as proportions of the total respondents and ranked using the rank correlation test.

\section{RESULTS}

\section{Study Population}

A total of 34 research staff members from 38 enrolling sites across Ontario completed the survey. Thus, the response rate was $89 \%$, which is an excellent rate likely to eliminate the chance of nonresponse bias in the results [26].

The median age of the respondents was 42 years of age (IQR: 29-45). Over half (59\%) of the research personnel that responded identified as Caucasian, $21 \%$ identified as African, Caribbean, and Black (ACB) with the remaining group reporting other ethnic minority groups. Thirty-two percent had less than 5 years of experience in the research field whereas $26 \%$ had between 5 and 10 years of experience. Fifty-six percent were located within an ASO, $38 \%$ from a clinic site, $15 \%$ from a hospital and one from a $\mathrm{CHC}$. Table 1 further summarizes the demographic characteristics of the sample.

\section{Recruitment Barriers}

The barriers to recruitment for HIV-positive women of reproductive age living in Ontario were determined in two parts: 1) identification of recruitment barriers found to be important to the surveyed research personnel and 2) rank order of the important barriers identified (as shown in Fig. 1). Fifty-nine percent of respondents identified the sensitive nature of the research topic as an important recruitment
Table 1. Demographic characteristics of the study participants (N=34).

\begin{tabular}{|l|rl|}
\hline Characteristics & No & (\%) \\
\hline \hline Age (Mean (SD) & 39.0 & $(10.2)$ \\
\hline Gender & 31 & $(91)$ \\
\hline Female & 3 & $(9)$ \\
\hline Male & & \\
\hline Race/Ethnicity & 20 & $(59)$ \\
\hline Caucasian & 7 & $(21)$ \\
\hline Black/African/Caribbean & 1 & $(3)$ \\
\hline Asian (Chinese/Japanese/Korean/Vietnamese) & 3 & $(9)$ \\
\hline Southeast Asian (Indian/Pakistani/Sri Lankan) & 3 & $(9)$ \\
\hline Other (Latin American/Aboriginal) & & \\
\hline Job Title & 7 & $(21)$ \\
\hline Research coordinator & 2 & $(6)$ \\
\hline Research assistant & 7 & $(21)$ \\
\hline Support services worker & 7 & $(21)$ \\
\hline Support services coordinator & 4 & $(12)$ \\
\hline Case manager/Project manager & 5 & $(15)$ \\
\hline Nurse & 2 & $(6)$ \\
\hline Executive directors & 19 & $(56)$ \\
\hline Site Type * & & $(3)$ \\
\hline Clinic & & \\
\hline Hospital & & \\
\hline AIDS service organization & & \\
\hline Community health centre & & \\
\hline
\end{tabular}

SD, standard deviation; * The sum of response options is greater than $100 \%$ because survey respondents may describe more than one option.

barrier, as it related to sexual and reproductive health. It was also ranked as the most important barrier overall. The same number of responders (59\%) also felt that lack of time and availability for potential study participants was a significant recruitment barrier and it was ranked as the second most important barrier overall. The third most highly reported, and ranked, recruitment barrier was associated with language and communication challenges and $53 \%$ identified this barrier as important. Language barriers included communication difficulties, unavailability of documents in languages other than English or French, and languages spoken by the research staff and participants. The fourth most important barrier ranked was the fear of deliberate or accidental disclosure of HIV status and concerns of stigma with $47 \%$ of respondents identifying it as an important barrier. Forty-one percent felt that the lack of trust of study personnel, fear of research trials, child care access, and transportation were important recruitment barriers which were ranked $5^{\text {th }}, 6^{\text {th }}, 7^{\text {th }}$, and $10^{\text {th }}$ in terms of level of importance respectively. The $8^{\text {th }}$ and $9^{\text {th }}$ ranked recruitment barriers were lack of trust with the study investigator (38\%) and complex language used in the survey $(35 \%)$. 


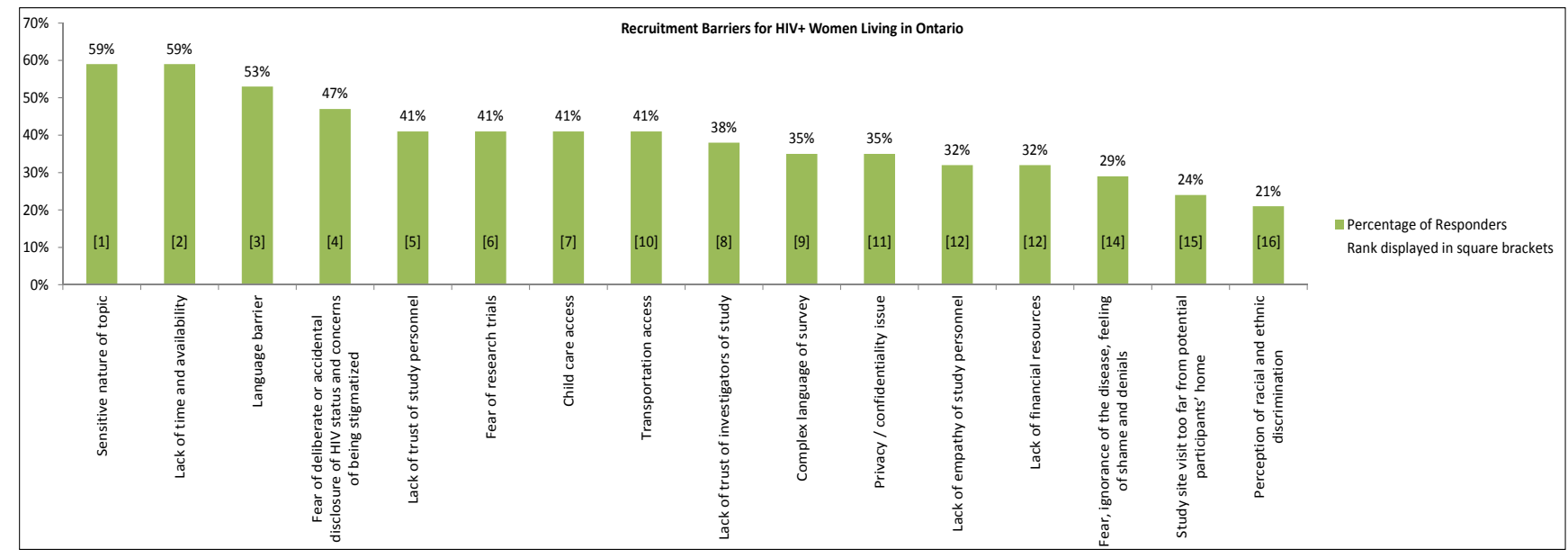

Fig. (1). Percentage and ranking of barriers to recruitment. Study participants were asked to select all potential barriers to recruitment from a pre-established list, and then to rank order the barriers they had identified. While some barriers had equal percentage and ranking scores (sensitive nature of the research topic was ranked highest and was identified by the most percentage, 59\% of respondents). Other barriers were ranked lower than the frequency at which they were identified by respondents (transportation costs was ranked $10^{\text {th }}$ despite being selected by $41 \%$ of respondents).

\section{Successful Recruitment Strategies}

The successful recruitment strategies for HIV-positive women of reproductive age living in Ontario were determined using the same process as barriers; identification of recruitment strategies found to be successful and rank order of the successful strategies identified. As described in Fig. (2), all responders $(100 \%)$ felt that rapport between the study personnel and participant being facilitated by study personnel who are empathetic was ranked the most successful recruitment strategy. Ninety-four percent of participants indicated that successful recruitment strategies for HIV-positive women involve the acknowledgment of the sensitive nature of the research topic. This recruitment strategy was ranked as the second most successful strategy overall. The third ranked most successful recruitment strategy is a cash reimbursement with $88 \%$ of responders indicating that it is a successful recruitment strategy. The same percentage of respondents $(88 \%)$ also indicated that there needs to be a strong rapport between the study personnel and participant which was ranked as the fourth most successful recruitment strategy as well as the use of recruitment strategies that are unique to women. In addition, $85 \%$ of responders felt that the most important factor for recruiting HIV-positive women is trust between her and the study personnel which was ranked as $6^{\text {th }}$. Responders ranked flexibility and the understanding that HIV-positive women require different recruitment strategies than that for HIVpositive men as the $7^{\text {th }}$ most successful recruitment strategies as $82 \%$ felt both to be an important recruitment strategy.

\section{Attributes of Research Personnel for Successful Recruitment}

The important attributes of research personnel for successful recruitment were also determined in two parts including identification and ranking in order of the important attributes of research personnel. Fig. (3) illustrates that responders found the following attributes in research personnel important for successful recruitment of HIVpositive women: respect (97\%) which was ranked most important, empathy (88\%) which was ranked second most important, a person who is skilled/knowledgeable about the research topic $(91 \%)$ which was ranked third most important, good communication skills $(88 \%)$ which was ranked $4^{\text {th }}$ most important and flexibility $(88 \%)$ which was ranked $5^{\text {th }}$ most important.

\section{Research Personnel's Insight}

During the Project Advisory Committee meetings, the years of insight from the research personnel, along with that of the community and the research team, highlighted the unique strategies needed to recruit women with HIV into all forms of research. Primary themes across the meetings included the tendency of women to need facilitated referrals to studies by someone they know and trust (i.e. telephone calls made by coordinators or support workers as opposed to flyers or study poster tear-offs); the need for financial support to attend study visits and secure childcare; the paramount importance of trust including opportunities to complete data collection with friends, in groups, and with peers; and finally that the research must be meaningful to women, as a collective, if they are to give their time and share their stories or samples. This insight that was possessed by the research personnel was used to better understand the data that emerged during analysis and to substantiate the perceptions expressed in the survey.

\section{DISCUSSION}

We found that research personnel clearly recognize barriers and facilitators to the recruitment of HIV-positive women. Consistent with previous research, we found that the recruitment of minority HIV-positive women into research requires careful consideration and cannot be assumed to mirror recruitment approaches in less marginalized populations who possess higher levels of personal agency in terms of research participation $[6,7,10,14,15]$. Gender is a significant socio-demographic variable that has been highlighted during research discussions among front line staff conducting recruitment, with women being noted as 


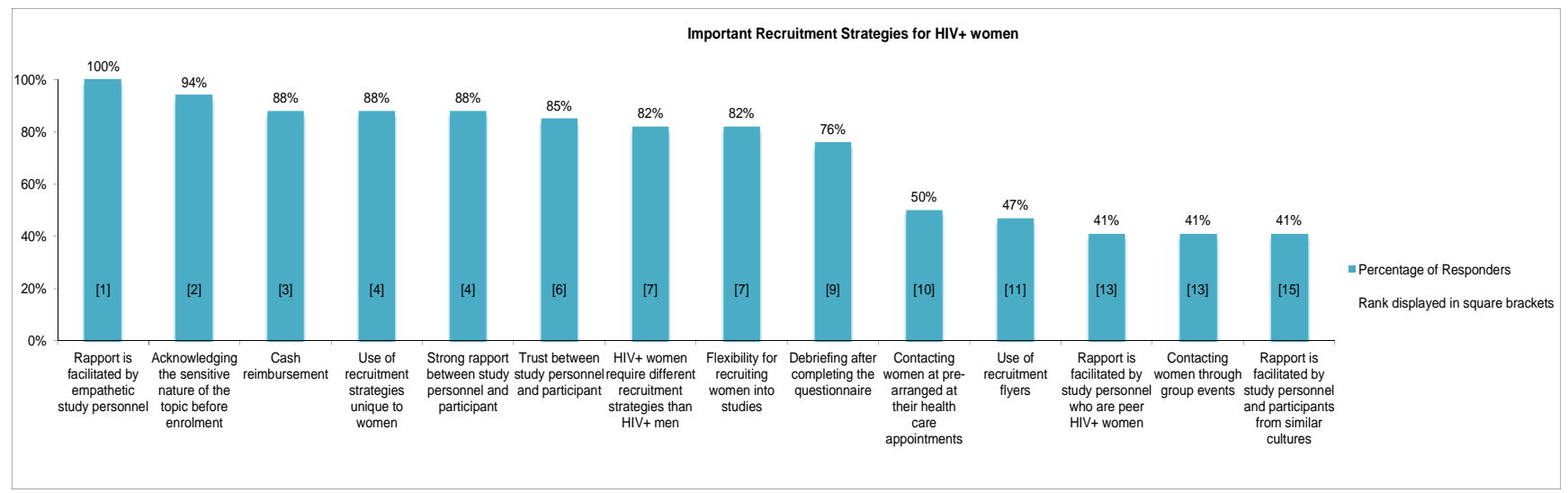

Fig. (2). Percentage and ranking of strategies for the recruitment of HIV-positive women. The percentage of respondents that identified pre-established recruitment strategies, and their ranking, is shown. Recruitment strategies were found to often mirror recruitment barriers. For example, acknowledging the sensitive nature of the research topic before enrolment was identified by the second highest number of respondents $(96 \%)$ and was ranked second overall as a recruitment strategy. It was identified as the number one barrier by in percentage and ranking.

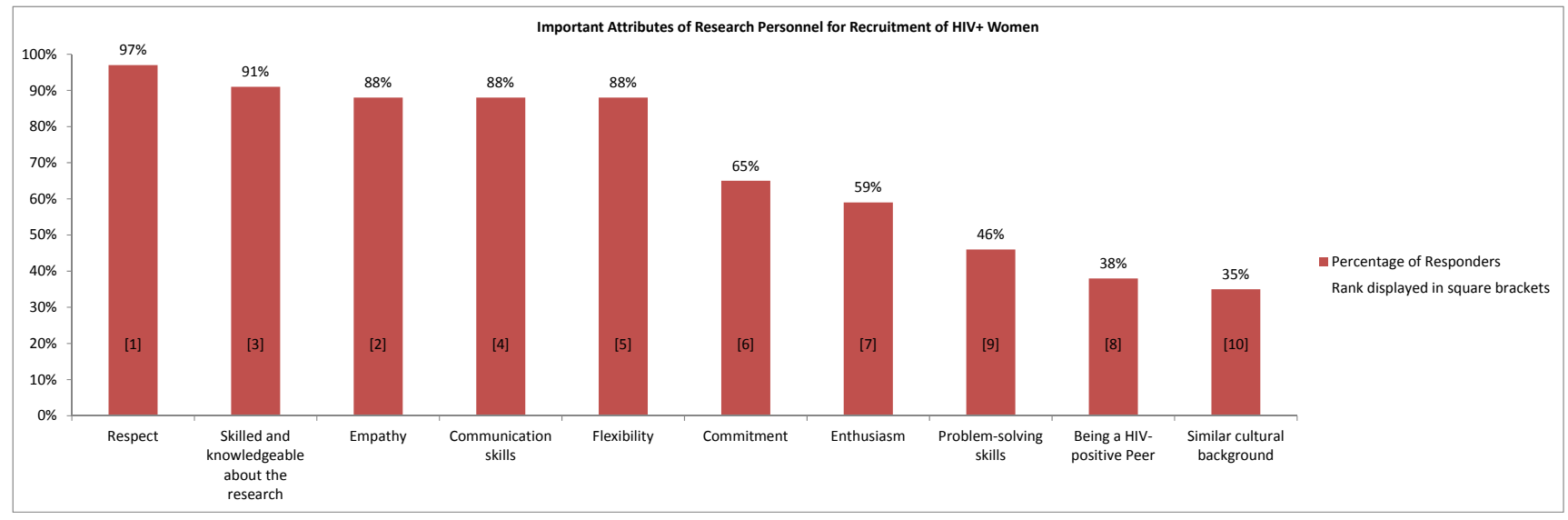

Fig. (3). Percentage and ranking of important attributes of research personnel for successful recruitment of HIV-positive women. Study participants were asked to describe important attributes of research personnel in order to successfully recruit HIV-positive women. There was no statistical difference in responses based on demographic characteristics of respondents (insert statistic).

less likely to engage independently in research than men. This finding is congruent with conceptual literature examining the relationships between gender, marginalization and personal agency, which posits that structural alterations are needed within systems that perpetuate the inability of marginalized communities, particularly women, to enact their personal agency [27]. In this instance, we assert that these structures are conventional approaches to research recruitment and the historical assumption that unique approaches for women, particularly minority women, do not exist.

The majority of research personnel (59\%) identified the sensitive nature of the research topic and ranked it as the most important recruitment barrier. HIV is itself a sensitive topic and adding to this is the fact that a great deal of research involving HIV-positive women focuses on the highly personal topics of sexual and reproductive health. Previous research suggested fear and lack of knowledge of HIV infection, itself, as perceived barriers towards participation in clinical trials among HIV-positive individuals [15]. The current findings reveal that 'fear' may also include fear of discussing or revisiting sensitive topics. This is largely influenced by social-political forces and has been felt by research personnel to be a greater barrier when recruiting women than factors associated with the HIVinfection itself. As such, the current study adds to our understanding of how to engage women in HIV research by focusing on the inherent issues associated with HIV and related topics as highly sensitized social phenomena. Lack of time and availability for participation was also found to be an equally important recruitment barrier for minority women in Ontario, a finding well supported in both HIV and other clinical research [28]. However, the current study begs the important question of how time constraints may uniquely hinder the engagement of women in HIV research and how research personnel can address this during recruitment. Researchers need to be more cognizant of the time constraints placed on women related to work, parenting, caring for elderly family members, and other familial responsibilities and consider practical solutions to support enrolment including childcare support and transportation 
[29]. By providing these solutions other constraints faced by study participants, including transportation and the cost involved with participating research, may better be addressed. Qualitative research with potential research participants could be used to corroborate this finding and further explore possible solutions.

Our finding that language barriers and communication difficulties were important recruitment barriers may not be unique to women but may have unique considerations for women. We build on these findings by referring to evidence of the lower language proficiency observed among female migrants than male migrants [30]. In Ontario, a considerable proportion of women living with HIV are not native English or French speakers. Our finding, in concert with these data, would suggest that language proficiency is a greater barrier to recruitment for women than men. However, it is not merely language but cultural communication practices that can be a hindrance between minorities and care providers [31]. Qualitative researchers have historically been mindful of issues associated with personnel from different cultural or racial backgrounds than participants (outsider researcher) and considered how these differences might effect data collection and analysis [32]. However, quantitative researchers have been less considerate of how these differences might hinder or alter recruitment. While the current study did not identify similar cultural background as one of the most important attributes identified by research staff, it is a worthy consideration to keep in mind and requires follow up with the possible study participants.

The final major recruitment barrier faced by research staff in the current study is lack of trust between the research personnel and study participants. The need for trust between research personnel and participants was corroborated repeatedly in the Project Advisory Board meetings. This is further complicated by historical experiences of minority groups in research that included deception, cohesion, and abuse [33]. The lack of trust may be a result of the study participants' fear of research trials due to misconceptions and misinformation surrounding research [34]. These misconceptions, which are common among minority groups, include conspiracies about the source of HIV, HIV vaccines and cures, underrepresentation of minorities due to bias, and safety of study participation [34], can also lead to negative perceptions of research personnel's attitudes including perceived ethnic and racial discrimination. Development of rapport, including an environment of mutual respect between participant and personnel prior to trying to engage them in research will help to facilitate this trust.

These recruitment barriers can be defined collectively as individual/personal barriers, socio-cultural barriers, research barriers, and economic barriers. Individual/personal barriers are the most abundant in the current data, which appear to be related to experiences of stigma. Stigma issues, including the sensitive nature surrounding HIV and the negative experiences of HIV-positive women, have lead to refusal to participate or difficulties expressing thoughts and feelings with respect to the research topic [35]. These issues seem to be a key reason why the HIV/AIDS population is difficult to engage in research as identified in our study as well as other studies $[1,7,15]$. Another individual/personal deterrent for recruitment is lack of time and availability to participate in the research due to a busy lifestyle including work and family obligations $[5,9,15,18]$.

While obvious barriers emerged in the data, so too did approaches that can be used to strengthen recruitment efforts. The most successful recruitment strategy identified in our study is the rapport between the research personnel and participant. Respondents unanimously felt that successful recruitment strategies should involve a rapport between the study personnel and study participant requiring respect, empathy, trust, skill and flexibility on the part of the study personnel. The characteristics of skill and flexibility can be achieved through training and research design however respect, empathy, and trust are more complex. While we did not find any literature that exists on the issue of rapport between participants and personnel in quantitative or clinical researcher, we can borrow from qualitative research wisdom, which often suggests that the development of rapport is essential to the redistribution of power that in turn allows for honest, transparent data collection [36, 37]. These qualitative data have been echoed in meetings that have been used to contextualize the current study's findings. These issues of respect, trust, and empathy may be further complicated for HIV-positive women who often have histories of abuse of power; this is an important area for future research to consider strategies to further diminish power imbalances and ensure trust and empathy.

Although King and his colleagues [9] presented a similar study assessing the attitudes and perceptions of site coordinators on the recruitment and retention of HIVpositive individuals, the study coordinators included males and females from clinical trials. The point of recruitment into clinical trials versus an observational trial is important. The current study is unique as it assessed recruitment barriers and strategies within observational studies from the perspective of diverse research team members who were all women and were located in different sites such as clinics, hospitals, ASOs, and CHCs. The heterogeneity of the sample may better allow the current findings to be valid and reliable in other types of research. The lessons learned from the current study and contextual data corroborate King et al.'s findings about the need to address logistic barriers to research recruitment of minorities and thus are transferable, as the screening, recruitment and baseline visits are similar research practices in all study design. While observational study designs may pose less intrinsic barriers for HIVpositive women as compared to trials, were exclusion criteria often exclude women who have a potential to become pregnant, beyond eligibility all study designs face the same challenges in enrolment. The issue of how to adapt inclusion/exclusion criteria of clinical trials to increase the admissibility of HIV-positive women with a high likelihood of conception, as in the original cohort of study participants, also requires further investigation.

The differences in race/ethnicity between our survey respondents, who were largely Caucasian, and the HIVpositive study population who were largely ACB is another important consideration from this study. At first glance this difference does not appear to be an issue that influenced recruitment outcomes as only $21 \%$ of the survey respondents felt that their perception of racial/ethnic discrimination was identified as a recruitment barrier. Upon deeper 
consideration, more questions emerge about this finding; for example, racial issues as a barrier may have been more readily perceived by certain racial/ethnic groups within the respondents. For example, it is worth noting that $21 \%$ of respondents identified as $\mathrm{ACB}$, the same number who identified racial/ethnic discrimination as a recruitment barrier. It is also impossible to determine if $\mathrm{ACB}$ respondents may have been more prolific recruiters in the original study among ACB participants as we did not collect the site name of current respondents to protect confidentiality. If so, the issue of racial/ethnic discrimination as a recruitment barrier would be difficult to determine within the current group. While the data support our previous statement that while racial differences can be a barrier, when these differences are managed with sensitivity they can be overcome, a deeper exploration of the nature of this barrier is required both the uncover the context of the barrier and also to identify strategies to increase sensitivity.

\section{LIMITATIONS}

Our study has several limitations. The generalizability of the research findings is limited by the small sample recruited for the current project. While response rate was high (89\%), the overall sampling frame was small which resulted in a sample of 34 research personnel participants. However, the recruitment sites and patterns where quite varied in this study from posters within ASOs to direct recruitment by a research personnel within an academic clinical setting. The heterogeneity in both site and recruitment pattern lends strength to the generalizability of these findings. A second limitation is that research personnel were surveyed rather the participants themselves and the research personnel's perspectives are being used as a surrogate for the true experience of the participants. In addition, a comparison of those who responded with research personnel who did not complete the survey may have added insight to the findings. This could play into under-representing the importance of some barriers and successes; as an example possible study participants may feel that having the study personnel be of the same cultural background may be more important than identified. A third limitation of the current study is the generalizability of findings beyond HIV research as results demonstrated strong issues related to HIV specifically as a barrier to recruitment. While these findings may not generalize, they are imperative for HIV researchers as recruitment of minority women is to improve. Finally, the rudimentary analysis that was feasible based on the small sample size (ranking and rating) is recognized as a limitation as is the inability to conduct any sub-analysis by staff demographic factors. The analysis may have also been strengthened by including a qualitative component beyond the existing contextual data available. None the less, the dissemination of this study is important given that the topic of recruitment of women with HIV in research remains under-addressed.

\section{CONCLUSION}

Our study has several strengths despite these limitations. To our knowledge this is the first study to examine the perceptions of research personnel in recruiting minority women into an observational HIV study. The findings were strengthened by the contextual data reported from extensive meetings with research team and community members. Findings support the conceptualization that enrolment of women possesses unique challenges related to gender roles and increased experiences of stigma, highlighting the salient issue of structural changes to the recruitment of women. This points to the urgent need for further research to understand these findings in greater depth across diverse stakeholder groups.

\section{CONFLICT OF INTEREST}

There are no conflicts of interest to declare from any of authors.

\section{ACKNOWLEDGEMENTS}

We thank the study participants, the frontline AIDS Service Organization staff and research coordinators, and the members of the Project Advisory Committee. We also thank the research personnel who took the time to fill out this survey.

This work was supported by peer-reviewed grants from the Canadian Foundation for AIDS Research (Grant \# 018-033) and the Ontario Ministry of Health and Longterm Care, AIDS Bureau.

\section{REFERENCES}

[1] Alvarez RA, Vasquez E, Mayorga CC, Feaster DJ, Mitrani VB Increasing minority research participation through community organization outreach. West J Nurs Res 2006; 28(5): 541-60.

[2] Morse EV, Simon PM, Besch CL, Walker J. Issues of recruitment, retention, and compliance in community-based clinical trials with traditionally underserved populations. Appl Nurs Res 1995; 8(1): 8-14.

[3] Hessol NA, Schneider M, Bacon M, et al. Retention of women enrolled in a prospective study of HIV infection: impact of race, unstable housing, and use of HIV therapy. Am J Epidemiol 2001; 154: 563-73.

[4] Robinson KA, Dennison CR, Wayman, DM, Pronovost PJ, Needham, DM. Systematic review identifies number of strategies important for retaining study participants. J Clin Epidemiol 2007; 60(8): 757-65.

[5] Grant JS, DePew DD. Recruiting and retaining research participants for a clinical intervention study. J Neurosci Nurs 1999; 31(6): 357-62.

[6] Gwadz MV, Leonard NR, Nakagawa A, et al. Gender differences in attitudes toward AIDS clinical trials among urban HIV-infected individuals from racial and ethnic minority backgrounds. AIDS Care 2006; 18(7): 786-94.

[7] Kelly PJ, Cordell J. Recruitment of women into research studies: A nursing perspective. Clin Nurse Spec 1996; 10(1): 25-8.

[8] Gifford AL, Cunningham WE, Heslin KC, et al. Participation in research and access to experimental treatments by HIV-infected patients. N Engl J Med 2002; 346: 1373-82.

[9] King WD, Defreitas D, Smith K, et al. Attitudes and perceptions of AIDS clinical trials group site coordinators on HIV clinical trial recruitment and retention: a descriptive study. AIDS Patient Care STDS 2007; 21(8): 551-63.

[10] Hankins C, Lapointe N, Walmsley S. Participation in clinical trials among women living with HIV in Canada. Can Med Assoc J 1998: 159: $1359-65$.

[11] At a Glance - HIV and AIDS in Canada: Surveillance Report to December $31^{\text {st }}$, 2011. Public Health Agency of Canada Web site. http://www.phac-aspc.gc.ca/aids-sida/publication/survreport/2011/ dec/index-eng.php. Accessed June 13, 2013.

[12] HIV Among Women. Center for Disease Control and Prevention Web site. http://www.phac-aspc.gc.ca/aids-sida/publication/survr eport/2011/dec/index-eng.php. Accessed June 13, 2013.

[13] Global summary of the AIDS epidemic. WHO, UNAIDS, UNICEF Web site. http://www.who.int/hiv/data/2012_epi_core_en.png. Accessed June 13, 2013. 
[14] Gilliss KL, Lee KA, Gutierrez Y, et al. Recruitment and retention of healthy minority women into community-based longitudinal research. J Womens Health Gend Based Med 2004; 10(1): 77-85.

[15] Gross CP, Mallory R, Heiat A, Krumholz, HM. Reporting the recruitment process in clinical trials: who are these patients and how did they get there? Ann Intern Med 2002; 137(1): 10-6.

[16] UyBico SJ, Pavel S, Gross CP, et al. Recruiting vulnerable populations into research: a systematic review of recruitment interventions. J Gen Intern Med 2007; 22(6): 852-63.

[17] Escobar-Chaves SL, Tortolero SR, Masse LC, Watson KB, Fulton JE. Recruiting and retaining minority women: findings from the women on the move study. Ethnic Dis 2002;12: 242-51

[18] Kressin NR, Meterko M, Wilson NJ. Racial disparities in participation in biomedical research. Natl Med Assoc 2000; 92(2): 62-9.

[19] Stone VE, Mauch MY, Steger K, Janas FS, Craven DE. Race, gender, drug use and participation in AIDS clinic trials. J Gen Intern Med 1997; 12: 150-7.

[20] Witte SS, El-Bassel N, Gilbert L, et al. Recruitment of minority women and their main sexual partners in an HIV/STI prevention trial. J Womens Health 2004; 13: 1137-47.

[21] Sullivan PS, McNaghten AD, Begley E, Hutchinson A, Cargill VA. Enrollment of racial/ethnic minorities and women with HIV in clinical research studies of HIV medicines. J Natl Med Assoc 2007; 99(3): 242-50.

[22] d'Arminio Monforte A, González L, Haberl A, et al. on behalf of Women for Positive Action. Better mind the gap: addressing the shortage of HIV-positive women in clinical trials. J Acquir Immune Defic Syndr 2010; 24(8): 1091-4.

[23] Walmsley SL. HIV-positive women in clinical trials: A gap in the facts. HIV Treatment Update 2010; p.197.

[24] Bassett R. Iterative: Sage research methods Web Site. http://srmo. sagepub.com/view/encyc-of-case-study-research/n185.xml. Access on September 30, 2014

[25] Loutfy MR, Hart TA, Mohammed SS, et al. Fertility desires and intentions of HIV-positive women of reproductive age in Ontario, Canada: a cross-sectional study. PLoS One 2009; 4(12): e7925.

[26] Johnson TP, Wislar JS. Response rates and nonresponse errors in surveys. JAMA 2012; 307(17): 1805-6.
[27] University of Manitoba. Andersen and Newman Framework of Health Services Utilization. Available at: http://www.umanitoba.ca/ faculties/medicine/units/mchp/protocol/media/Andersen_and_New man_Framework.pdf

[28] Ross S, Grant A, Counsell C, Gillespie W, Prescott R. Barriers to participation in randomised controlled trials: a systematic review. J Clin Epidemiol 1999; 52(12): 1143-56.

[29] Brown-Peterside P, Chiasson MA, Ren L, Koblin B. Involving women in HIV vaccine efficacy trials: Lessons learned from a vaccine prepared ness study in New York City. J Urban Health 2000; 77(3): 425-37.

[30] Ng E, Pottie K, Spitzer D. Official language proficiency and selfreported health among immigrants to Canada. http://www statcan.gc.ca/pub/82-003-x/2011004/article/11559-eng.htm. Accessed on September 30, 2014.

[31] Van Wieringen JCM, Harmsen JAM, Bruijnzeels MA. Intercultural communication in general practice. Eur J Public Health 2002; 12(2): 63-8.

[32] Nelson J, Gould J. Hidden in the mirror: a reflective conversation about research with marginalized communities. Reflect Pract 2005; 6(3): 327-39.

[33] Katz RV, Russell SL, Kressin NR. The Tuskegee Legacy Project willingness of minorities to participate in biomedical research. J Health Care Poor Underserved 2006; 17(4): 698-715.

[34] Priddy FH, Cheng AC, Salazar LH, Frew PM. Racial and ethnic differences in knowledge and willingness to participate in HIV vaccine trials in an urban population in the Southeastern US. Int J STD AIDS 2006; 17(2): 99-102.

[35] Logie CH, James L, Tharao, W, Loutfy MR. HIV, gender, race, sexual orientation, and Sex work: A Qualitative study of intersectional stigma experienced by HIV-positive women in Ontario, Canada. PLOS Med 2011; 8(11): e1001124.

[36] Karnieli-Miller O, Strier $\mathrm{R}$ Pessach L. Power relations in qualitative research. Qual Health Res 2009; 19: 279-89.

[37] Guillemin M, Heggen K. Rapport and respect: negotiating ethical relations between researcher and participant. Med Health Care Philos 2009; 12(3): 291-9. 